The Integration of Fieldwork and Survey Methods

Author(s): Sam D. Sieber

Source: American Journal of Sociology, Vol. 78, No. 6 (May, 1973), pp. 1335-1359

Published by: The University of Chicago Press

Stable URL: http://www.jstor.org/stable/2776390

Accessed: 19/05/2011 16:19

Your use of the JSTOR archive indicates your acceptance of JSTOR's Terms and Conditions of Use, available at http://www.jstor.org/page/info/about/policies/terms.jsp. JSTOR's Terms and Conditions of Use provides, in part, that unless you have obtained prior permission, you may not download an entire issue of a journal or multiple copies of articles, and you may use content in the JSTOR archive only for your personal, non-commercial use.

Please contact the publisher regarding any further use of this work. Publisher contact information may be obtained at http://www.jstor.org/action/showPublisher?publisherCode=ucpress.

Each copy of any part of a JSTOR transmission must contain the same copyright notice that appears on the screen or printed page of such transmission.

JSTOR is a not-for-profit service that helps scholars, researchers, and students discover, use, and build upon a wide range of content in a trusted digital archive. We use information technology and tools to increase productivity and facilitate new forms of scholarship. For more information about JSTOR, please contact support@jstor.org.

The University of Chicago Press is collaborating with JSTOR to digitize, preserve and extend access to American Journal of Sociology. 


\title{
The Integration of Fieldwork and Survey Methods ${ }^{1}$
}

\author{
Sam D. Sieber \\ Columbia University
}

\begin{abstract}
A historical antagonism between the proponents of qualitative fieldwork and of survey research has prevented recognition of the benefits to be gained by employing both methods in the same study. Each method can be greatly strengthened by appealing to the unique qualities of the other. Through examination of a number of cases in which the methods have been integrated, it is possible to discern important benefits in design, data collection, and analysis. In order to fully exploit the advantages of integration, however, adjustments in traditional procedures will have to be made, thereby yielding a new style of social research.
\end{abstract}

Prior to World War II, fieldwork ${ }^{2}$ dominated social research. Such classics as the Hawthorne studies, the Middletown volumes, the Yankee City series, and the Chicago studies of deviant groups, not to mention the anthropological contributions, attest to the early preeminence of fieldwork. Following the war, the balance of work shifted markedly to surveys. This shift was largely a consequence of the development of public-opinion polling in the thirties. Mosteller, Cantril, Likert, Stouffer, and Lazarsfeld were perhaps the major developers of the newer techniques. In particular, Lazarsfeld's interest in the two major nonacademic sources of social surveysmarket studies and public-opinion polling-and his adaptation of these traditions to substantive and methodological interests in sociology gave special impetus to the advancement of survey research in the universities.

With the rapid growth of this vigorous infant, there emerged a polemic between the advocates of the older field methods and the proponents of the newer survey techniques. In fact, two methodological subcultures seemed to be in the making - one professing the superiority of "deep, rich" observational data and the other the virtues of "hard, generalizable" survey data. That the fieldworkers were more vocal about the informational weaknesses of surveys than were survey researchers with respect to fieldwork suggests the felt security of the latter and the defensive stance of the former. An extreme point in the polemic was reached by the statement of

1 We are especially indebted to John D. Ferguson for his stimulating ideas regarding the interplay of fieldwork and surveys.

2 That is, participant observation, informant interviewing, and use of available records to supplement these techniques in a particular setting. 
Becker and Geer (1957): "The most complete form of the sociological datum, after all, is the form in which the participant observer gathers it; an observation of some social event, the events which precede and follow it, and explanations of its meaning by participants and spectators, before, during, and after its occurrence. Such a datum gives us more information about the event under study than data gathered by any other sociological method. Participant observation can thus provide us with a yardstick against which to measure the completeness of data gathered in other ways" (p. 28).

This position was strongly contested in a rebuttal by Trow (1957), who pointed out that no single technique could claim a monopoly on plausibility of inference; and, indeed, as he argued, many sociological observations can be made only on the basis of a large population. One technique is suitable for one type of information and another technique for another: "It is with this assertion, that a given method of collecting data-any method-has an inherent superiority over others by virtue of its special qualities and divorced from the nature of the problem studied, that I take sharp issue.... Different kinds of information about man and society are gathered most fully and economically in different ways. . . The problem under investigation properly dictates the methods of investigation" (p. 33).

In his brief rebuttal, Trow did not seek to propose a scheme for determining the suitability of fieldwork or survey research for the collection of given types of data. This task was undertaken a few years later by Zelditch (1962), who applied the criteria of "efficiency" and "informational adequacy" of surveys, participant observation, and informant interviewing in gathering three kinds of data: (1) frequency distributions, (2) incidents and histories, and (3) institutionalized norms and statuses. Thus, if the objective is to ascertain a frequency distribution, then the sample survey or census is the "prototypical and best form"; but not so with incidents and histories, which render the survey both "inefficient and inadequate," according to Zelditch. This contribution was a long step forward in mediating between the two historically antagonistic styles of research.

But even this formulation showed the traces of an assumption that undergirded the earlier polemic, namely, that one uses either survey or field methods. The fact of the matter is that these techniques are sometimes combined within a single study. If all three types of information noted by Zelditch are sought within the framework of a single investigation, then all three techniques are properly called into play. In such cases, the inefficiency of a survey in studying "institutionalized norms and statuses" falls by the wayside; if one is conducting a survey anyway (because of other information needs), then why not proceed to measure norms and statuses in the questionnaire? Likewise with the investigation of incidents and histories by means of a survey. If combined with other ap- 
proaches, according to Zelditch, the survey becomes "adequate" for the collection of incidents and histories; so if one is already doing a survey, the question of efficiency once again becomes irrelevant. But there is a second implication of combining field and survey methods that is much more important to the progress of social research than the needed qualifications in Zelditch's scheme.

The integration of research techniques within a single project opens up enormous opportunities for mutual advantages in each of three major phases-design, data collection, and analysis. These mutual benefits are not merely quantitative (although obviously more information can be gathered by a combination of techniques) but qualitative as well-one could almost say that a new style of research is born of the marriage of survey and fieldwork methodologies. Later on, we shall argue that the respective techniques need to be modified for their special roles in a set of interlocking methods. It is this combination of adjustments which, in our opinion, produces a distinctly new style of investigation.

It is curious that so little attention has been paid to the intellectual and organizational problems and to the prospects of the integration of research methods. A few methodologists have sought to compare the results of different approaches, but these endeavors were conceived within the traditional framework of mutually exclusive techniques, inasmuch as the problem was to determine the consequences of using either one or another technique.

The authors of a recent compendium of "unobtrusive measures" have noted our doggedness in viewing social research as a single-method enterprise: "The usual procedural question asked is, which of the several datacollection methods will be best for my research problem? We suggest the alternative question: which set of methods will be best?" (Webb et al. 1966, pp. 174-75). These authors were prompted to raise this question on the assumption that every technique suffers from inherent weaknesses that can be corrected only by cross-checking with other techniques: "No research method is without bias. Interviews and questionnaires must be supplemented by methods testing the same social science variables but having different methodological weaknesses" (p. 1). In its own way, this assumption is as radical as that of Becker and Geer. To be sure, there are areas of informational overlap between methods, but there are also large areas of information which can be gained only by a particular technique. If each technique has an inherent weakness it also has an inherent strength unmatched by other techniques. The opinions held by a large population can be measured only by survey techniques; the unverbalized normative pattern of a small group might be measurable only by observation. Further, what if the results obtained from two or more different techniques do not agree? Are we to abandon our findings altogether, or should we reexamine 


\section{American Journal of Sociology}

the techniques to discern a special weakness in one of them that invalidates its results? If the latter strategy is chosen, then we are admitting the superiority of one of the techniques in gathering the desired information. An illustration from a class experiment at Columbia University will make the argument more concrete.

\section{A Class Experiment ${ }^{3}$}

In a seminar on research methods, nine graduate students were provided with the field notes of an observer-informant interviewer who had investigated the settings of Job Corps trainees in two city agencies. On the basis of these notes, the project director had selected one of the settings as "good" and the other as "bad" in terms of the trainees' morale, opportunities for training, and meaningful participation in the work of the agencies. (Although several agencies had been investigated, these two were selected as polar cases for the purpose of the class experiment.) The nine students were instructed to scrutinize the field notes very carefully and then to select those items from a questionnaire (later distributed to the trainees) which they believed would confirm the conclusions of the project director as to the value of the two settings (the direction of the predicted difference being obvious in most cases since the items were clearly evaluative of morale, participation, etc.). After the students had made their individual selections, the results of the questionnaire survey in each of the two agencies were tabulated and compared item by item. If at least half of the judges predicted that an item would discriminate, and it did in fact discriminate, it was classified in a category of "congruence" between fieldwork and survey results. If less than half of the judges predicted a difference on the item, but the item nevertheless discriminated, it was classified in a "noncongruent" category; and so on. Table 1 shows the percentage of 75 questionnaire items that fell into each of four logical classes.

Table 1 discloses that $45 \%$ of the survey items were predictable on the basis of the field notes (cells 1 and 4). Virtually all of the items in cell 1 referred to the match between the trainee's interests and qualifications and the job he was performing. (Of all the items, $21 \%$ fell into this cell.)

Another $24 \%$ of the items were accurately regarded by the judges as revealing no difference (cell 4 ). The items in this category focused mainly on the administration of the overall program, such as selection procedures, training, general administration, etc.; in other words, experiences that the trainees in the two agencies were known to have shared. As these experiences were not specific to a particular agency, the judges assumed correctly that the items bearing on them would not discriminate between the agencies.

Cells 2 and 3 clearly reveal incongruence between the field notes and the survey results. In cell 2 we find items that in fact discriminated but that the field notes did not provide grounds for such discrimination (36\% of the items). This percentage may be taken as a rough measure of the

3 Catherine Bodard Silver was most helpful in analyzing the results of the experiment. We also appreciate the cooperation of George Nash in making available his data. 


\section{Integrating Fieldwork and Survey Methods}

TABLE 1

Questionnaire Items Classified according to Their Congruence with Fieldwork ObServations ( $\%$ of 75 Items)

\begin{tabular}{|c|c|c|c|c|c|}
\hline \multirow{2}{*}{\multicolumn{2}{|c|}{$\begin{array}{l}\text { ITEM ACTUALLY } \\
\text { DISCRIMINATED } \\
\text { BETWEEN } \\
\text { AGENCIES } \\
\end{array}$}} & \multicolumn{4}{|c|}{ Consensus among JUdges $\dagger$} \\
\hline & & & $\begin{array}{l}\text { Half or More } \\
(5-9)\end{array}$ & & $\begin{array}{l}\text { Less than Half } \\
(0-4)\end{array}$ \\
\hline Yes & $\ldots \ldots \ldots \ldots$ & (1) & $\begin{array}{l}\text { Congruence (prediction } \\
\text { of difference confirmed) } \\
21 \%\end{array}$ & (2) & $\begin{array}{l}\text { Noncongruence (failure } \\
\text { to predict difference) } 36 \%\end{array}$ \\
\hline No & 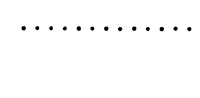 & (3) & $\begin{array}{l}\text { Noncongruence (in- } \\
\text { accurate prediction of } \\
\text { difference) } 19 \%\end{array}$ & (4) & $\begin{array}{l}\text { Congruence (prediction } \\
\text { of no difference con- } \\
\text { firmed) } 24 \%\end{array}$ \\
\hline
\end{tabular}

* $10 \%$ difference between the agencies was regarded as determining whether an item "discriminated." $\dagger$ No. of judges predicting a difference between survey responses of trainees in two city agencies on basis of field notes.

unique contribution of the survey as perceived by the judges. The items falling into this cell were of three distinct kinds: (1) statistical data such as number of hours per week with little or nothing to do, income expected from Urban Corps, present pay rate; (2) personal history such as how income compares with what was previously expected, whether another job was turned down to work for Urban Corps, attitude toward job when applied; (3) personal interests and values such as kinds of summer jobs preferred, enjoyment of life in the city, occupational values, career plans, interest in hearing different types of speakers in Urban Corps Seminars.

Perhaps more lengthy exposure to the agencies and their trainees would have contributed more information on these points in the field notes. However, the survey was clearly a more economical means of disclosing such information. In addition, by being gathered in a standardized fashion the information could be dealt with statistically in examining the differential impact of the two agencies on different trainees. For example, it now became possible to see if trainees with lower occupational aspirations were less satisfied with the "bad" agency.

Finally, in cell 3 we find items that were expected to discriminate but which in fact did not discriminate between the two agencies $(19 \%$ of the total items). Here it is plain that the field notes misled the judges into assuming that the trainees in the "bad" agency (1) were disliked by their superiors and other regular staff, and (2) blamed the agency itself for their unsatisfactory assignment. In short, an assumption of mutual animus was conveyed by the field notes. Here are some examples of items that were mistakenly thought to discriminate between the two agencies (in each case the trainees in the "bad" agency were expected to give the more negative response):

How do you think your supervisor would rate your performance?

If you have switched jobs, what were the reasons? (Agency or supervisor was dissatisfied.) job?

Have you complained to the Urban Corps staff about any aspect of your

When you first arrived in this agency, how much did the agency prepare you for what you would be doing? 
Do you like your supervisor as a person?

Would you say your non-Urban Corps co-workers are friendly or unfriendly to you?

How would you characterize your agency? As: (a) open to new ideas, (b) bureaucratic, (c) sympathetic toward clients.

We encounter here a common pitfall of fieldwork that might properly be called the "holistic fallacy"- that is, a tendency to perceive all aspects of a social situation as congruent. In the present instance, because of the wholly unsatisfactory job assignments of the trainees in one of the agencies, it was assumed that they would be displeased with the agency and, in turn, would feel resented by the regular agency staff. The survey corrected this assumption.

While the above experiment confirms Webb et al., in the advisability of using several techniques to validate inferences, it also demonstrates that certain information can be gathered only by means of a single technique (see cells 2 and 3 above). However, by drawing upon its special strengths, one technique may contribute substantially to the utilization of the other technique. It is this principle that we wish to demonstrate in the remainder of this essay.

To recapitulate: the original polemic between advocates of field methods and of survey research was mediated by the assertion of Trow and Zelditch that the nature of the problem dictates the method to be applied. Later on, Webb et al. rejected a commitment to any single method in solving a particular problem because of an inherent bias in all techniques. Their argument in behalf of multitechniques is based on an assumption of interchangeability-otherwise it would be meaningless to plead for crossvalidation. In contrast, we believe that survey and field research each possesses special qualities that render these methods noninterchangeable; nevertheless, each method can be greatly strengthened by appealing to the unique qualities of the other method.

Despite the plausibility of this claim, the advantages of the interplay between surveys and field methods are seldom recognized and rarely exploited. To the contrary, it seems that most sociological research either utilizes only a single method of investigation, or assigns an extremely weak role to a second. To show the value of fully integrating the respective techniques by drawing upon existing research for examples, we hope to focus serious attention on the enormous opportunities that lie at hand for improving our social research strategies.

We shall first deal with the contributions of fieldwork to surveys and then reverse ourselves and consider the contributions of surveys to fieldwork. In each case we shall give illustrations that bear on the phases of design, data collection, and analysis associated with each method.. Then, in a final section, we shall take up the question of time-order in which the

${ }^{4}$ All illustrations are indented and set in smaller type for easy reference. 
methods are applied. Considerations of time-order are of major importance to the management of a research study that seeks to benefit from both techniques. This point will become clearer when we turn to the formulation of an optimal research schedule.

\section{CONTRIBUTIONS OF FIELDWORK TO SURVEYS}

\section{Contributions to Survey Design}

More and more, surveys are conducted among selected communities or organizations rather than among samples of isolated individuals. In these cases, a great deal of careful thought must be given to the selection of the collective. It is not unusual, therefore, to find survey researchers scouting among an array of potential collectives in order to select those that promise to maximize the advantages of comparative study. An account of one such scouting expedition is given by Wilder and Friedman (1968, appendix A) who had tentatively selected seven communities to be included in their investigation of school-community relations. (Parents, students, and teachers in these communities were eventually interviewed.) We quote:

The Project Director and his assistant visited each of the communities to see whether they appeared to "fit" their census descriptions. Since we had found it necessary at several points to compromise with our a priori assumptions about what constituted criteria for the various types of communities, we had certain misgivings about some parameters and cutting points and we felt it would be useful to verify qualitatively our sampling framework. In addition we were curious to see these communities with which we had become so familiar on the basis of census data.

In general, the tours served to confirm our expectations. Schools in settled towns were often pre-1900 vintage, while in growing communities they were either new or had new additions. Homes and people in middle-class communities "looked" middle-class and shops displayed quality merchandise. In the working-class towns homes were smaller, lawns were tiny or non-existent, Methodist churches were predominant. Boxy developments were mushrooming in the growing working-class suburb, while more expensive split-level developments abounded in the growing middle-class suburb. The trips served to convince us that the communities we had selected on the basis of the available published data did indeed "fit" their census descriptions.

The contribution of field observations to the study design of a survey need not be restricted to a confirmatory role, as in the above example, but can provide the sole rationale for the design. An illustration is provided by our own research on suburban schools.

While conducting exploratory interviews and observations in a single suburban school system located just beyond the crest of a migratory wave originating in a large city, our attention was drawn to the school system's 
vulnerability as its public composition gradually changed. In our interviews, we heard stories about a neighboring system that had already felt the full impact of migration. The informants were fearful that the same kinds of conflict between school and community would overtake their own system in the near future. After about two months of fieldwork in the less urbanized system, we decided to include the neighboring system in our study and to focus on the response of the schools to increasing vulnerability arising from suburbanization. Fieldwork was then pursued in both systems for several months before launching a questionnaire survey of all staff members in the two systems. Thus, the initial fieldwork sharpened the focus of the investigation on a specific educational problem by directing attention to the contrast between pre- and post-suburbanized systems, necessitating the inclusion of a second system. A survey was then conducted to gain fuller knowledge of the impact of suburbanization on the schools. Fieldwork, in sum, dictated the design of the survey investigation.

Broadly conceived, qualitative fieldwork includes any source of personal familiarity with a setting or group to be surveyed. This knowledge may be derived from nonprofessional sources, such as family members or previous work experience. These sources can provide insights and "privileged" information that can make a major contribution to the development of a meaningful survey design. A striking illustration of the benefits of nonprofessional familiarity with a social group prior to the conception of a survey is afforded by Lipset (1964) in his "biography" of the project that eventuated in the well-known monograph, "Union Democracy." Lipset's interest was in explaining the high level of participatory democracy in the printers union, a phenomenon that disconfirmed classical theories of the development of oligarchical control in socialist parties and trade unions. An innovation of the project was the sampling of collectives (union chapels), a design permitting elaborate analysis of contextual effects on individual political attitudes and behaviors. Referring to this unusual design, Lipset says: "The methodological innovations evidenced in our sample design did not stem from any special concern with creative methodology. ... It was a sophisticated survey design precisely because years of prior investigation of the attributes of a complex system had preceded it" (p. 125). The history of that prior investigation began in Lipset's youth: "My first contact with the International Typographical Union came when I was quite young. My father was a lifelong member of the union. . . . While in elementary school and high school, I frequently overheard discussions of union matters, and occasionally my father would take me to the monthly meetings of the New York local at Stuyvesant High School-a set of experiences which was to play a role later in my conceiving of the 'occupational community' as an important part of the environment of the union" (p. 112). Lipset's survey design was developed expressly to study the effect of varying degrees of "occupational com- 
munity" within the different chapels in promoting the members' political participation.

The contribution of field methods to survey design is by no means restricted to the study of collectives. Sometimes, for example, there are special categories of individuals whose existence is brought to light by exploratory fieldwork and which are then incorporated into the design of the survey.

In preparing for an investigation of the organization of research in schools of education, in which deans and bureau directors were to be surveyed, Lazarsfeld and I (1966; Sieber 1972) interviewed expert informants. One informant noted the presence of "faculty research coordinators," an emerging status that had been overlooked in the study design. The informant himself filled this role in his institution. Therefore a special questionnaire was prepared for these persons. Further, since we realized that the data to be collected from these respondents would permit a comparison of organized and unorganized settings for research, the former represented by bureau directors and the latter by faculty coordinators, the existing questionnaires were modified by expanding the number of items on which comparisons would be fruitful. In effect, a new study design was adopted. These comparisons later afforded a perspective on bureau research that was not attainable in any other way.

\section{Contributions to Survey Data Collection}

The exploratory interviews and observations that often precede social surveys yield valuable information about the receptivity, frames of reference, and span of attention of respondents. Since a great part of the value of systematic pretesting resides in the gathering of such intelligence, it is justifiable to consider this aspect of pretesting under the rubric of qualitative fieldwork. Improvements in the questionnaire stemming from qualitative pretest information enhance rapport between interviewer and respondent, reduce nonreturns of mailed questionnaires or refusals to be interviewed, and generally ease the data-collection efforts of the research staff.

In addition, the instrument can be broadened or narrowed, depending upon the identification of topics that are salient to pretest respondents. That is, by identifying the respondents' level of interest and scope of concern, the instrument can be modified to avoid overtaxing each respondent, on the one hand, or underrepresenting his views, on the other. An example of expanding a questionnaire on the basis of this type of information is taken from a survey of college students on a single campus. A chronicle of the questionnaire's development (Langenwalter 1967) contains the following observation:

The pre-test was administered to about thirty students, and the results were very heartening. Almost all of the interviewers reported that the 


\section{American Journal of Sociology}

respondents seemed to be interested in cooperating. This information caused an over-all change in the form of the questionnaire. In the pre-test, the emphasis had been on limiting the number of questions for fear of antagonizing the busy students. The interviewers' reports seemed to indicate that the fear was ungrounded and the items that had been limited could be expanded.

The general direction of the expansion was the addition of contingent sections to existing questions. . . . The discovery of student interest allowed us to add more sections according to our own interests. [Pp. 5-6]

Pretesting is only one means of exploring issues that bear on the development of an instrument. Often a good deal of exploratory work precedes even the pretest questionnaire. As a rule, the more knowledgeable the questionnaire designer about his ultimate population, the more sophisticated the instrument and the smoother its administration.

Apart from the formulation of the questionnaire, fieldwork often provides a means of gaining legitimation for the survey. If the population has a central leadership, contacts with leaders will often smooth the way for contacts with followers. If there are factional fights, of course, the endorsement of only a single leader may set a large number of the followers in opposition to the survey. But information about political in-fighting should come to the attention of the sophisticated fieldworker in the normal course of informant interviewing, thereby prompting him to gain endorsements in a way that will appeal to all sectors of the constituency.

The importance of identifying and gaining support from the appropriate authority during the exploratory phase preceding a survey, and of grasping the political context in which approval is sought, are perhaps best demonstrated by a negative instance.

Voss (1966) describes the case of a school survey that was terminated by the superintendent on the grounds that it was "unauthorized by the school." Although in reality the superintendent was responding to pressures from a group of right-wing parents, the survey having been duly approved by lower level administrators, he was able to claim that he had not personally endorsed the survey and could therefore cancel it on legalistic grounds. Voss concludes from this experience: "Lack of familiarity with the structure of the organization may spell disaster. For some time sociologists have recognized that persons without portfolio may influence the decision of the titular head of the organization. The only means of avoiding such a problem is to obtain unequivocal support from the highest level possible."

Our investigation of two suburban districts, mentioned earlier, affords a case at the opposite end of the spectrum of cooperation.

After conducting fieldwork for several months-which included the privilege of walking unannounced into the superintendents' offices at any hour and attending closed strategy meetings of the teachers' associationthere was never really any question of gaining endorsements for the 
survey. Every administrator in the district cooperated fully in urging teachers to respond and in collecting the completed questionnaires. And the many helpful, marginal comments of the teachers, some addressing the survey designer by name, suggested that the questionnaire was completed with uncommon seriousness. (The return rate was about $90 \%$ of the entire staff.)

The two projects are not exactly parallel since Voss surveyed students rather than staff members, thereby touching off community hostility; but the problems encountered by Voss are also faced in gaining access to school staff. The crucial point is that rapport which stems from fieldwork can smooth the way for the more elaborate, time-consuming, and often more threatening aspects of survey data collection. Apparently, the impersonality of a survey can be counteracted by the subjects' personal acquaintance with the investigator and the goals of his study.

\section{Contributions to Survey Analysis}

Information that is gathered in the course of fieldwork can assist in the analysis and interpretation of survey data in several ways. First, the theoretical structure that guides the analysis can be derived wholly or largely from qualitative fieldwork. Second, as emphasized by Webb et al. (1966), certain of the survey results can be validated, or at least given persuasive plausibility, by recourse to observations and informant interviews. (This contribution is limited to areas of informational overlap, as noted earlier.) Third, statistical relationships can be interpreted by reference to field observations. Fourth, the selection of survey items for the construction of indices can be based on field observations. Fifth, external validation of statistical constructs (indices) is afforded by comparison with observational scales. Sixth, case studies that illustrate statistical and historical types are supplied by field protocols. Seventh, provocative but puzzling replies to the questionnaire can be clarified by resort to field notes. Illustrations of each of these contributions to survey analysis follow.

1. The derivation of a theoretical structure from fieldwork is perhaps more common than appears from reports of survey work. Often, only passing acknowledgment is made of prior, personal familiarity with the situation, a familiarity that has produced rather definite ideas for research. A sociologist who conducts a survey of college faculty has made many observations of his own institutional context which contributed, no doubt, to his theoretical guidelines, but his monograph might omit any reference to this fact. And rare indeed is the report that systematically traces the intellectual history of a study to its qualitative antecedents.

Such an effort has been made by Lipset in his chronicle of the "Union Democracy" study (Lipset 1966). As a consequence of his personal famil- 


\section{American Journal of Sociology}

iarity with the International Typographers Union, Lipset says, "I had a fairly clear picture in mind of factors which had created ITU democracy and those which sustained it. ... The main task of the survey was to convert hypotheses which had been developed earlier into questions for a schedule which could be administered to a sample of union members" (pp. 123-24).

In an investigation of high school rebellion, Stinchcombe (1964) asserts that the four hypotheses that guided his analysis "were developed during the course of about six months of anthropological observation and exploratory survey research in a California high school" (pp. 9-10). In the preface to his monograph, Stinchcombe candidly notes his debt to informant interviewing: "I became quite suspicious of any hypothesis that was never formulated, in one guise or another, by at least one of the teachers or administrators of the school, and many were suggested by them." It would appear that an optimal schedule for theoretical survey research would include a lengthy period of fieldwork prior to the survey. As a result of our perusing the literature for examples, however, our impression is that this practice is rarely followed.

2. The verification of survey findings by reference to fieldwork is especially useful when the finding is both surprising and strategic. A statistic of this kind was discovered in our study of educational research organizations (Sieber and Lazarsfeld 1966).

Tabulation of the questionnaire showed that extremely few doctoral recipients who had worked in research bureaus as assistants remained as staff members. On the average, only .7 students per unit had stayed on after the doctorate in the past three years. It occurred to us that this fact might explain the lack of continuity in research bureaus, the difficulty of recruitment and the strong influence of each succeeding director. Here was an explanatory factor that was wholly unanticipated. But since only about two-thirds of the respondents had answered this difficult statistical question, we felt uneasy about resting our case on the survey finding alone. When we later did informant interviewing, therefore, we asked the directors how they felt about retaining research assistants as professional staff members. With only one exception, the dozen or so directors whom we talked to believed that students should be encouraged to leave the bureau after getting their degrees. The reason given was that students would not become independent of their mentors unless they took positions elsewhere. Since this viewpoint was expressed with great conviction by the informants, the field interviews lent plausibility to the survey finding.

The invalidation of survey results by qualitative methods should also be counted as a contribution to survey analysis. For example:

In her study of working-class marriage, it was very important for Komarovsky (1962) to classify her subjects according to differing degrees of marital happiness in as reliable a manner as possible, for marital happiness was a crucial dependent variable. She therefore drew upon in- 
formation gathered in a series of detailed and indirect probes. Comparing her distribution of cases with large, representative samples of the same social strata which employed more direct self-ratings, she found that her own population contained a larger proportion of unhappy marriages. In one nationwide survey only $5 \%$ of the grade school graduates were classified as "not too happy"; while in her study, $14 \%$ were judged to be "very unhappy." Komarovsky accounts for this discrepancy by reference to the more subtle techniques of qualitative case study, making it more difficult for the respondent to conceal the unpleasant aspects of marital relations. As she states: "Our detailed and indirect probing may have brought to light unfavorable facts which are not readily admitted in answer to direct questions used in surveys. . . . In our own interview, answers to the direct questions on dissatisfaction with communication were at variance with the admissions made elsewhere by the same people" (p. 348). Consequently, instead of being misled by the results of typical survey items, Komarovsky employed a more qualitative approach when classifying her subjects according to certain major variables in her study.

The testing of a survey's reliability may extend to the entire study as well as focusing on selected items or variables. Riesman visited a large number of the social science professors who had been interviewed in the study of threats to academic freedom during the McCarthy years (Lazarsfeld and Thielens 1958). He also interviewed the interviewers. As a result, he was able to arrive at the overall assessment of the survey's reliability. $\mathrm{He}$ states in Lazarsfeld and Thielens: "Deficiencies in the interviewing did not seriously impair the information gathered. Or, to put it another way, the interviewing was, in general, sufficiently skillful to carry the somewhat unusual demands of this particular survey" (p. 269).

3. Qualitative fieldwork is also useful for the interpretation of statistical relationships. The identification of a whole series of interpretative variables is illustrated by Kahl's study of "common man" boys (1953). Kahl found that IQ and occupation contributed independently to students' plans to attend college. He then became interested in the chain of causality linking SES to college aspirations. Through intensive interviews with the parents of a small subsample of the students (i.e., those in the upper lower and lower middle brackets) who had completed questionnaires, he found that overt parental pressure largely accounted for the students' college plans. This variable had not been measured in the original survey. Kahl then proceeded even farther in his search for interpretive variables by discerning those factors that impelled the parents to urge college upon their children. The following is my own synopsis of his findings on this point.

Parents who propelled their children toward college had adopted the upper middle class as a normative reference group, frequently owing to the father's proximity to middle-class workers within his job setting. Because

5 The term "interpretive variable," as used here, denotes a variable that intervenes in time between two variables whose relationship is already established. 
these better trained and higher paid employees had high visibility for the father, he had become dissatisfied with his own occupational role and therefore placed great emphasis on his children's getting ahead. Those who were content for their children to stay out of college seemed more oriented to peers rather than to individuals placed immediately above them in the work hierarchy. Moreover, these fathers were not socially acquainted with professionals or semiprofessionals. Consequently, they tended to exhibit "short-run hedonism," that is, a concern with present enjoyments rather than with delayed gratifications. Rather than "getting ahead," as Kahl puts it, they were interested in "getting by."

In summary, Kahl's interview materials permitted him to refine the original survey correlation between SES and college plans among high IQ "common man" boys whose chances of planning to attend college were about 50-50.

Direct observation of behavior may also aid in the interpretation of a statistical relationship. The following example is drawn from our own study of suburban schools.

In the questionnaire, the teachers in the two suburban systems were asked if they had easier access to administrators than most other teachers. In the smaller, less bureaucratized system, teachers with easier access held more favorable attitudes toward the administration. This was not the case in the larger district, however, where access and attitudes were unrelated. I tried to recall any difference that was observed between the two districts in the nature of personal interaction between teachers and administrators. By reflecting on my observations of actual meetings, I noted a distinction which had escaped me before. In the larger district both teacher and administrator observed formal protocol in the course of interaction. For instance, appointments were made, the participants sat with rigid postures on opposite sides of the administrator's desk, and the discussion pursued a business-like course. In the smaller district, the situation was highly informal. The teacher walked unannounced into the administrator's office, the participants sat back comfortably at a large conference table and enjoyed a smoke together, and the conversation roamed over a variety of topics. In short, a considerable amount of social distance was maintained in teacher-administrator relations in the larger district, reflecting the widely shared bureaucratic norms in that district. Consequently, personal sentiments of liking or disliking did not arise from teacher-administrator contacts. In the smaller district, the distance between formal ranks was almost obliterated by personal friendships, making it possible for mutual trust to develop more readily out of frequent interaction.

4. The construction of indices for use in survey analysis may derive from systematic informant interviewing or from more casual observation. The value of informants is demonstrated by Carlin's study of the social factors affecting the ethical behavior of lawyers (1966).

Before the analysis could precede, it was necessary to develop a scale to measure the ethical proclivities of the lawyers. Therefore, questionnaire items were assembled from information about the ethical conflicts that commonly arise in legal practice. Much of this information was gleaned from informal interviews with lawyers. Carlin gives the following account 
of his strategy: "Detailed interviews were conducted with a dozen lawyers. They were asked certain general questions relating to professional ethics; also, they were asked to identify borderline unethical practices. Among the general questions were the following: In what ways do lawyers take advantage of other lawyers? In what ways do lawyers act unethically toward public officials? What kinds of activities do you consider unethical or improper? How do you distinguish more from less ethical lawyers? How important are such distinctions in your judgments of other lawyers?" Several hypothetical situations that presented opportunities for unethical conduct were eventually devised. Responses to these items in the questionnaire made it possible to score the lawyers according to their ethical tendencies.

A similar approach was employed in the development of an index of "apprehension" on the part of social science professors regarding threats to academic freedom (Lazarsfeld and Thielens 1958). The authors discuss the development of this index in great detail, but what interests us here is the preliminary phase of exploratory interviewing.

The first step was to conduct a series of detailed interviews with a number of college professors who were prevailed upon to describe in detail any situation encountered in their capacity as teachers which had somehow made them feel uneasy. We asked them to remember as much as they could of both important and trivial experiences which create problems in a teacher's professional career, experiences they had already encountered or which might arise in the future. From these preliminary interviews we selected a list of about twenty relatively specific experiences. Questions were then worded so that the respondent simply had to say whether or not these things had happened to him. . . . Twenty-one items were included in the questionnaire to gauge a professor's apprehension. But further screening was necessary to select the items most suitable for the classificatory task at hand. . . As a result of this sifting, eleven items remained suitable for an index of apprehension. [Pp. 73-74]

5. The validation of a statistical index by reference to fieldwork is illustrated by our procedure in testing a measure of "formal authority" among the directors of research bureaus.

The index was based on replies to such questions as whether the director participated in the decision to undertake a study, whether he determined the salaries and promotions of staff members, whether he was a member of the board of directors, etc. After each director had been scored on the index, a small subsample was visited to gain firsthand information about certain bureaus. In the course of the interviews with the directors, the interviewer sought to explore the amount of formal authority that the directors had. Finally, the directors were told that they ranked high, low, or medium on the index and asked if their score accurately reflected their position. In virtually all cases, the directors confirmed their position on the index. One director who scored very low on the index explained that he ran the bureau in a very informal manner but nevertheless had a great deal to say about what went on. Further probing revealed that the director in question was a highly esteemed scholar who was frequently 
sought out by the staff for advice and support. Thus, we were alerted to a weakness in the index that was later compensated for by using a measure of the directors' research productivity to reflect their informal status among colleagues.

6. The use of case studies to illustrate statistical and historical types that are derived from survey analysis is so common a practice that it only seems necessary to refer to it here. Some investigators who have employed this technique are Kahl (1953), Gordon (1957), Komarovsky (1962), and Sieber and Lazarsfeld (1966). In all these cases-and the reader can undoubtedly think of his own examples-fieldwork reports were used to exemplify certain types of individuals or situations that were disclosed in the analysis of survey data.

7. A final contribution of fieldwork to survey analysis entails the clarification of ambiguous but provocative responses to a questionnaire.

In our survey of the directors of educational research bureaus, we asked the following: "In general, how fruitful have interchanges been with the academic departments in the university; what problems have been encountered, if any; and what directions would you like future interchanges to take?" One director wrote the following reply: "Professors in the liberal arts seem not to be able to make advancements within their respective departments if they participate heavily in the activities of the Center." The response was curious, possibly significant, but far from clear. Later, in the course of fieldwork among selected bureaus, we asked the director to clarify his answer. He explained that academic personnel who became associated with his organization lost visibility in their departments. Their frequent absence from the department was interpreted as a lack of departmental commitment. His clarification illuminated the problem of integrating research bureaus into the universities, which became a dominant theme in our subsequent thinking.

\section{CONTRIBUTIONS OF SURVEYS TO FIELDWORK}

We now shift to the other end of the two-way street between fieldwork and survey methodologies. The contribution of surveys to fieldwork is probably less well appreciated than the reverse; but as we shall see, there are many ways in which fieldwork can take advantage of survey techniques. Indeed, on many occasions it would seem to be methodologically obligatory.

\section{Contributions to the Design of Fieldwork}

We noted earlier that fieldwork is useful for identifying the most suitable collectives or individuals to be surveyed. The same holds for the contribution of surveys to the design of fieldwork.

When selecting collectives or individuals for qualitative case study, it is common to rely upon a statistical profile of the population containing the 
units to be observed. For example, in selecting schools for intensive fieldwork, we might peruse the following kinds of information about a number of districts: racial and occupational composition, density, school size, teachers' salaries, etc. These data are often used because they are readily available. But there is frequently a need for other information which is more pertinent to the goals of a study. Thus, a field exploration of the school characteristics that promote innovative behavior would benefit from precise data showing the range of "innovativeness" among a number of schools. With this information in hand, it would be easy to select schools at different points on the continuum for qualitative study. Other kinds of information that are not generally available but might be collected in a preliminary survey include staff morale, educational goals of parents or school personnel, backgrounds of school board members, and proportion of graduates who attend college. For example, before visiting the research units for our fieldwork (in connection with the study of graduate schools of education), we stratified the units according to certain data already collected in a national survey. The degree of emphasis on research versus service, whether the unit mainly facilitated faculty research or staff research, and public or private sponsorship were the stratifying variables. The first two items of information were contributed by the survey.

The purpose of selecting the research bureaus according to a sampling frame was to provide cases that represented the main types of bureaus. Another use of survey data is to select unrepresentative cases for the analysis of subtypes.

As an example, Kahl (1953) used survey data to select a particular subsample of students and their parents for intensive interviewing. $\mathrm{He}$ examined the distribution of all cases according to IQ, fathers' occupations, and the students' expectations of college attendance. Those students whose plans were least predictable on the basis of IQ and fathers' occupationthat is, high IQ and low occupation-were selected for follow-up study.

Kahl selected subjects who conformed to his theoretical expectations but who were under the cross-pressures of relatively low occupational background and high IQ. Consequently, only about half planned to attend college. The purpose of his follow-up interviews was to find out what distinguished the college- from the non-college-going students in this group. He might have chosen, however, to study those students who went counter to his expectations, for instance, the boys of high IQ and high occupational background who did not intend to enroll in college $(11 \%$ of his cases); or the boys of low IQ and occupational background who did intend to enroll in college $(9 \%)$. If he had adopted this approach in refining his theory, he would have been engaged in what has come to be known as "deviant case analysis." As Kendall and Wolf (1949) point out, "Through careful analysis of the cases which do not exhibit the expected behavior, 
the researcher recognizes the oversimplification of his theoretical structure and becomes aware of the need for incorporating further variables into his predictive scheme" (pp. 153-54). But often the researcher does not have in hand the additional information necessary for measuring the further variables. Since it is extremely rare for a survey researcher to reenter the field for intensive interviewing after the completion of a survey, the needed information is almost never collected. This methodological embarrassment might account for the superficiality of a good many reports based on survey analysis.

Qualitative fieldworkers, of course, also search for relationships among variables. But since evidence that can be examined in tabular form is seldom collected, the identification of deviant cases is more difficult than in survey work and therefore more prone to escape attention. Here is where a preliminary survey can be most fruitful, for it constrains the fieldworker to notice departures from theoretical expectation and clearly identifies those cases that deviate. The fieldworker can then focus on these cases for intensive observation.

In sum, a survey can improve the design of fieldwork by identifying both representative and unrepresentative cases, the former serving the goal of generalizability and the latter the function of theory refinement.

\section{Contributions to Fieldwork Data Collection}

A common pitfall in qualitative data collection is an "elite bias" in the selection of informants and in the evaluation of statements. There are several reasons for gravitating to the elite of a social system in the course of fieldwork. First, initial contacts are often made with the "gatekeepers" of a group to insure access to subjects. Consequently, the fieldworker tends to feel gratitude toward the elite and is careful to keep on good terms with them, especially in the early period while establishing his credentials. These early constraints on the fieldworker's role might color his objectivity throughout the ensuing study. Second, if the upper-status persons are esteemed in society at large, the fieldworker might tend to value personal association with them to the detriment of other contacts. Such overvaluation might stem from the prestige conferred on the sociologist by familiarity with (and later specialization in) a certain elite strata. A third reason for the elite bias is that upper-status individuals are often more articulate and give the impression of being better informed about the group than any other member. Thus, they might seem to display greater knowledge and equanimity, enhancing their qualification as informants. Finally, it is often more interesting to study elites who have remained hitherto inaccessible to sociologists than to study lower-level participants, even though a goal of the study might be to observe all strata. Consequently, the fieldworker 
might spend more time collecting information from the elites, ultimately giving greater weight to their viewpoints than to those of lower-level participants.

With hindsight, all of these factors probably entered into our own fieldwork in a study that set out to examine the structure of two suburban school systems, but developed into a study of school boards, superintendents, and the leaders of the high school teachers. After conducting a survey, however, I was able to correct certain impressions that emerged from my elite bias. This can be shown quite simply. Prior to looking at the results of the survey, I predicted the proportion of teachers who would respond in particular ways to the survey questions. I then compared my predictions with the actual responses. It became obvious when observing these comparisons that I had unwittingly adopted the elites' version of reality. For example, I overestimated the extent to which teachers felt that the administration accepted criticism. Here are the relevant questions and the statistics: "Do you think that teachers who are interested in administrative openings jeopardize their opportunities in this district by voicing criticism of present school policies and practices?" (\% responding "definitely" and "possibly") :

\begin{tabular}{|c|c|}
\hline System A & $\begin{array}{l}\text { Predicted } \\
\quad 40\end{array}$ \\
\hline System B . . . . . . . & 40 \\
\hline
\end{tabular}

Similarly, I had assumed that the teachers were more satisfied with evaluative procedures than was in fact the case: "All in all, how well do you think the evaluation of teachers is done in your school?" (\% responding "as well as possible" and "fairly well"):

\begin{tabular}{|c|c|c|}
\hline System A: & Predicted & Observed \\
\hline Elementary & 80 & 65 \\
\hline Secondary & 50 & 36 \\
\hline \multicolumn{3}{|l|}{ System B: } \\
\hline Elementary & 80 & 74 \\
\hline Secondary & 75 & 56 \\
\hline
\end{tabular}

Although to a lesser extent, I also overestimated the rank-and-file support for the leaders of the teachers association, with whom I had spent a good deal of time. In short, I had fallen prey to the elite bias, despite recent training in the dangers of giving greater weight to prestigious figures as informants.

The survey not only constrained me to see that my qualitative datacollection procedures had been faulty, but also provided the opportunity to learn about an entire stratum which I was aware of having glossed over in the fieldwork, namely, the elementary teachers. Apparently the elite bias had operated also in my preference for secondary teachers, who are the more esteemed both in the profession and the community.

If the survey results had been available to me in the midst of fieldwork, I would have been able to alter my data-collection procedures. This sort of concurrent scheduling of field- and survey work was utilized by Vidich and Shapiro (1955) in their study of a rural community. 
The field observer, who had spent a year in the community, sought to rank a large sample of residents according to certain prestige groupings. A sociometric survey was then conducted among these individuals. In comparing the results, it was found that individuals who were not known to the observer contained a disproportionate number of those with low prestige. As the authors put it on page 31, "Thus, even though the observer had made deliberate efforts to establish contact with lower prestige groups, his knowledge of community members was biased in favor of individuals with higher prestige. ... Without the survey data, the observer could only make reasonable guesses about his areas of ignorance in the effort to reduce bias. The survey data give him more exact information regarding the degree and kind of selectivity operating, and thereby allow him to make better compensatory allowances in planning his observational activities."

As in my own case, moreover, the field observers were now able to classify a large number of cases with whom they were unacquainted. In sum, here are two ways in which surveys contribute to data collection in fieldwork: (1) they correct for the elite bias in the interpretation of events, and (2) they provide information about the informants or subjects who were overlooked.

There are other contributions, too, providing that the survey is conducted prior to fieldwork. Replies to survey questions provide leads for later interviews and observations and eliminate the need to ask routine "background" questions. They thereby afford greater realism, enhance rapport, and offer guidelines for probes.

Before arriving for our appointments with the directors of research bureaus, we carefully studied the information they had given us in the questionnaires. Background data on the directors and routine organizational information gave us an imagery of the man and his setting. And it was especially helpful to be able to forgo asking tedious questions about the activities, structure, and purposes of the organization. As a result, the interviews were relaxed, focused on subtle points of research administration, and relatively brief. In certain instances, replies to the mailed questionnaire were followed up with probes.

\section{Contributions to the Analysis of Qualitative Field Materials}

We will discuss four contributions of surveys to the understanding of field observations: (1) correction of the holistic fallacy, (2) demonstration of the generality of a single observation, (3) verification of field interpretations, and (4) the casting of new light on field observations.

1. Correction of the holistic fallacy.-In our earlier discussion of a class experiment in predicting survey results from fieldwork, we referred to the "holistic fallacy" as a tendency on the part of field observers to perceive all aspects of a social situation as congruent. This tendency is a common pitfall. The anthropological method was developed in response to the needs 
of studying a particular type of social setting-small, isolated, relatively homogeneous cultures. In transferring the method to industrial societies, certain intellectual assumptions underlying the technique were also transferred, that is, every social situation can be perceived in an ideal-typical fashion. When the search for congruence overrides important refinements or dictates assumptions that are unsupported by direct evidence, and especially when striking exceptions to one's theory are subtly discounted in behalf of a unified conception, one is indulging in the holistic fallacy.

It will be recalled that this tendency was demonstrated in the class experiment reported earlier: evidence that the trainees were poorly suited for their assignments was extended to their attitudes toward supervision, when in fact the survey showed that these trainees felt no more hostile toward supervisors than trainees in a more satisfactory work setting. Another example of the holistic fallacy corrected by survey results is drawn from our study of suburban schools.

It was our impression that the smaller school district approximated the Gemeinschaft form of society, while the larger one was much more bureaucratized, impersonal, up-to-date, that is, a Gesellschaft setting. In pursuing the fieldwork, I became more and more convinced that this distinction applied to almost all aspects of the two systems and would be reflected in the attitudes of the participants.

The survey seemed to confirm that there was greater social cohesion in the smaller district. When asked how many of the faculty were close personal friends, $21 \%$ in the smaller district stated six or more, while only $7 \%$ in the other district claimed as many personal friends. But other results upset my expectations. With respect to the perception of red tape ("an excessive number of rules and regulations which hamper the abilities of the staff of my school") there was no difference. And with respect to the perception of faculty morale and cohesion the attitudes of the staff in the larger district were clearly more favorable. Overall, there turned out to be many more similarities than differences between the two districts. Apparently, my observation of greater informality among the staff members in the smaller district had led me to assume that morale in general was higher, and that less strain was created by bureaucratic regulations because of the informal nature of the administration. Thus, the survey made it possible to refine the attitudinal climate so as to disconfirm those impressions that had arisen from the holistic fallacy.

2. Demonstration of the generality of a single observation.--Surveys also afford the means of demonstrating the generality of a single observation. When the observation plays an important role in the theoretical structure of fieldwork, survey data become essential for buttressing the argument. The following illustration is taken from a comparative study of school boards (Kerr 1964).

The field observer was impressed by the superintendents' unwillingness to allow board trustees to discuss educational matters, including those 
that fell legally within the board's domain. The observation was critical for Kerr's thesis that superintendents sometimes convert the boards into "legitimating agencies" in order to preserve professional autonomy. Since only two superintendents were observed, Kerr was uncertain as to the generalizability of their attitudes. By referring to the results of a survey conducted among the staff, he was able to show that the resistance to legally constituted lay control was generally held by school administrators. We quote from pages 51-52: "The superintendents were not the only administrators in the districts who disapproved of the boards' intervention in professional matters which legally came under the boards' jurisdiction. For example, a questionnaire survey in the districts included a question concerning the role that the school board should play in hiring teachers: 'To what extent do you think the following persons or groups should influence the selection of new teachers?" Eight out of 13 administrators in one district and five out of eight in the other replied that the school board should be "not at all" involved in selecting teachers.

Since legally all personnel appointments had to be approved by the board members, the survey finding confirmed the hostility of professional educators to the nominal authority of school trustees. Kerr then showed how this attitude led to manipulative measures in the interest of protecting professional autonomy.

3. Verification of field interpretations.-The verification of observations based on fieldwork is a third, major contribution that surveys make to the analysis of field materials. Here we return to the point made by Webb et al., that multiple techniques are often necessary for the validation of results.

In the course of fieldwork among medical students, Becker et al. (1961) were impressed with what they called the "long-range perspective" of the freshmen students, a perspective characterized by a vague notion of the physician's role and an idealistic view of medicine. According to the researchers, the students conveyed this perspective mainly "by gesture and tone of voice" and "the innumerable other nuances of human interaction impossible to record or quantify." In addition to the field data, however, they had materials from interviews with a random sample. When asked to express their idea of a successful physician, the freshmen rarely mentioned money, and generally responded in ways that reflected an idealistic conception. Also, it was found that the students decided on a medical career at an early age, and learned about the profession from the same sources as the public at large, that is, from movies, books, and from being patients. As the researchers sum up: "With data from the interviews thus supporting the field work, we conclude that freshmen enter medical school full of enthusiasm, pride, and idealism about the medical profession" (p. 79).

4. The casting of new light on field observations.--Survey results can cast a new light on field observations, or more precisely, the serendipitous nature of some survey findings can illuminate a field observation that was hitherto inexplicable or misinterpreted. It is common to think of fieldwork as being more congenial to serendipity than survey work. Sometimes we hear that surveys should be actuated by specific problems or hypotheses, 
while fieldwork is uniquely qualified for exploratory investigations. But survey analysts make many observations that were unanticipated; and in another context, I argue that surveys are uniquely qualified for the measurement of unanticipated concepts (Schenkel and Sieber 1969).

The exploratory portion of survey analysis can be exploited for the better understanding of field observations. A simple illustration will suffice.

In our study of two suburban districts, it was observed that a smaller proportion of teachers turned out to vote in the bond issue election in the larger district. When this observation was shared with informants, many explanations were offered. We tentatively attributed the poor turnout to the alienation of many teachers in the more bureaucratized system. (We have already seen that this holistic assumption was challenged by the survey data.) While perusing the distribution of responses to the survey, we noticed with surprise that $39 \%$ of the teachers in the larger district resided outside of the district, compared with only $18 \%$ in the smaller district. The teachers in the larger district were simply less often legally qualified to vote. The observations of poorer turnout was therefore reinterpreted. Moreover, we then began to explore the implications of living inside or outside the district for the teachers' involvement in the affairs of the system and in their relationships with parents.

\section{Problems of Scheduling}

Many of the examples that we have given depend upon a particular timeordering of field observations and survey work. Thus, the contribution of fieldwork to the formulation of the theoretical structure underlying a survey study requires that the fieldwork be performed prior to designing the survey study. But if the purpose of the fieldwork is to clarify or extend a survey finding, then it must be conducted after the survey. Further, several of our examples depended upon concurrent scheduling of the methods-correction of the elite bias in fieldwork, repeated pretests of a questionnaire, and perhaps also correction of the holistic fallacy. Further if the survey investigator is in the field during data collection, he might learn a great deal about the meaning of the survey questionnaire to respondents. To some extent, the "obtrusiveness" of a questionnaire can be assessed and taken into account in the analyst's interpretations. This latter information is sometimes conveyed to the survey worker by professional interviewers, but firsthand experience with the instrument during its administration is probably also needed. An optimal research schedule, therefore, would entail an interweaving of field observations and survey work over the duration of the project, regardless of the primary method of data collection. (If the techniques were assigned to different staff members having special competencies, the work load on the project director would be lightened.)

The problems of integrating survey and fieldwork are reduced when 
studying a small number of formally organized collectives, such as schools, since the respondents are clustered within settings having definite boundaries. But even the typical large-scale survey of individuals could be rearranged so as to profit from fieldwork. In the first place, respondents could be selected who are socially related to one another. These networks could then be treated in much the same fashion that a fieldworker deals with a more formal collective. If for some reason this type of survey design is not feasible, then every $n$th interviewer could be instructed to make certain observations or to extend the interview into an unstructured format. Such interviewers would have to receive special training in fieldwork, or they might be recruited from among individuals who have specialized in fieldwork in the past.

In other instances, the traditional design of fieldwork might need to be modified to take advantage of a survey. Certain clusters of actors might be identified; then, a large number of such clusters could be selected in order to enhance the usefulness of statistical study. Or networks of relationships could be sought in fieldwork in order to select individuals who will receive questionnaires.

The adjustments in traditional research designs called for by the integration of field and survey methods would seem to produce a new style of research. At present there are far too few examples of this style to adduce general principles to be followed in organizing future projects. The task of collecting specimens of projects that have sought to profit from the interplay of fieldwork and surveys, rather than instances bearing on a single aspect of projects, remains for the methodologist of the future-providing that the boundaries between the two traditions are dissolved and attention is turned to their intellectual integration in the interest of improving our strategies of social research.

\section{REFERENCES}

Becker, Howard S., and Blanche Geer. 1957. "Participant Observation and Interviewing." Human Organization 16 (Fall): 28-32.

Becker, Howard S., Blanche Geer, Everett C. Hughes, and Anselm L. Strauss. 1961. Boys in White: Student Culture in Medical School. Chicago: University of Chicago Press.

Carlin, Jerome E. 1966. Lawyer's Ethics: A Survey of the New York City Bar. New York: Russell Sage Foundation.

Gordon, C. Wayne. 1957. The Social System of the High School. Glencoe, Ill.: Free Press.

Kahl, Joseph A. 1953. "Educational and Occupational Aspirations of 'Common Man' Boys." Harvard Educational Review 23 (Summer): 186-203.

Kendall, Patricia L., and Katherine M. Wolf. 1949. "The Analysis of Deviant Cases in Communications Research." In Communications Research, 1948-49, edited by Paul F. Lazarsfeld and Frank W. Stanton. New York: Harper.

Kerr, Norman D. 1964. "The School Board as an Agency of Legitimation." Sociology of Education 38 (Fall): 34-59. 


\section{Integrating Fieldwork and Survey Methods}

Komarovsky, Mirra. 1962. Blue-Collar Marriage. New York: Random House.

Langenwalter, Suzanne. 1967. "History of a Questionnaire." Mimeographed. New York: Bureau of Applied Social Research, Columbia University.

Lazarsfeld, Paul F., and Wagner Thielens, Jr. 1958. The Academic Mind. Glencoe, Ill.: Free Press.

Lipset, Seymour M. 1964. "The Biography of a Research Project: Union Democracy." In Sociologists at Work, edited by Phillip E. Hammond. New York: Basic.

Schenkel, Walter, and Sam D. Sieber. 1969. The Design of Survey Questionnaires: A Case History Approach. Mimeographed. New York: Bureau of Applied Social Research, Columbia University.

Sieber, Sam D., and Paul F. Lazarsfeld. 1966. The Organization of Educational Research. Cooperative Research Project No. 1974 (USOE). New York: Bureau of Applied Social Research, Columbia University. See also Reforming the University: The Role of the Research Center. New York: Praeger, 1972.

Stinchcombe, Arthur L. 1964. Rebellion in a High School. Chicago: Quadrangle.

Trow, Martin. 1957. "Comment on 'Participant Observation and Interviewing: A Comparison.'" Human Organization 16 (Fall): 33-35.

Vidich, Arthur J., and Gilbert Shapiro. 1955. "A Comparison of Participant Observation and Survey Data." American Sociological Review 20 (February): 28-33.

Voss, Harwin L. "Pitfalls in Social Research: A Case Study." American Sociologist 1 (May 1966): 136-40.

Webb, Eugene J., Donald T. Campbell, Richard D. Schwartz, and Lee Sechrest. 1966. Unobtrusive Measures: Nonreactive Research in the Social Sciences. Chicago: Rand McNally.

Wilder, David E., and Nathalie S. Friedman. 1968. "Selecting Ideal-Typical Communities and Gaining Access to Their Schools for Social Research Purposes." In Actual and Perceived Consensus on Educational Goals between School and Community, by David E. Wilder, Nathalie S. Friedman, Robert B. Hill, Eva E. Sandis, and Sam D. Sieber. New York: Bureau of Applied Social Research, Columbia University. Zelditch, M., Jr. 1962. "Some Methodological Problems of Field Studies." American Journal of Sociology 67 (March): 566-76.

\section{Errata}

In Jessie Bernard's "My Four Revolutions," in the January 1973 issue of the Journal, she incorrectly refers to Martin Nicklaus's statement at the 1968 meetings of the American Sociological Association as Jack Nicklaus's (p. 775, n. 10). The latter was undoubtedly playing golf during those meetings, since that is his profession. 